\title{
Computational drug Cumintrazole-analog for the treatment of mutant BRCA1 and BRCA2 proteins in breast cancer
}

\author{
*Shehneela Baseer ${ }^{1}$, Sajid Khan ${ }^{1}$ and Faisal Nouroz ${ }^{2}$ \\ ${ }^{1}$ Department of Bioinformatics, Government Postgraduate College Mandian Abbottabad, Pakistan \\ ${ }^{2}$ Department of Bioinformatics, Hazara University Mansehra, Pakistan
}

\begin{abstract}
Breast cancer is the second death causing disease in the world. Breast cancer gene 1 (BRCA1) and Breast cancer gene 2 (BRCA2) are the controlling proteins of this cancer. Real capacity of BRCA1/BRCA2 is to control the cell division, repair the damaged DNA and stabilized the genetic material of the cell. In case of any mutation in these proteins, the division of breast cells will be modified and therefore the cancerous development of cells will start in breast. The essential target of study was to prepare novel synthetic compound to focus on destinations for receptor proteins, located on cells surface, which control the development or stop the multiplication of cancer cells. Subsequent to screening vast measure of information, we outlined novel in-silico medication compound for breast cancer that is able to hinder the uncontrolled development of cells. In docked edifices PHE and GLN are critical communicating build ups for BRCA1 and BRCA2 proteins. Atomic recipe of shad sample totally fulfills the Lipinski rule of five. It shows less symptoms and long resistance against breast cancer cells. We infer that our medication shad sample is better than the business drugs available in business sector. As it is non-toxic in nature and has no reactions. The proposed drug is suitable for reduction of the breast cancer in females.
\end{abstract}

Key Words: BRCA1, BRCA2, breast cancer, in-silico, mutation.

\section{INTRODUCTION}

Cancer is a syndrome, where the abnormal body cells grow and multiply uncontrollably. Breast cancer occurs when breast cells start to grow un-controlled, allowing them to affect nearby tissues and spread to the whole body. It was difficult to identify the hereditary basis of breast cancer five years prior, when the breast cancer susceptibility genes BRCA2 and BRCA1 genes were identified through positional cloning technique. After this discovery, it becomes clear that germ line changes or mutations in both BRCA1 and BRCA2 genes represent 20 to $60 \%$ of breast cancer cases in families (Nathanson et al., 2001). A little amount of transformation occurs, which causes changes in BRCA1 and BRCA2 proteins. These changes are slightly known and some are still unknown, which are involved in the familial breast cancer danger (Easton, 1999). Two main sites in the breast, where cancer is more dangerous are lobules (milk producing tissues) and the ducts named as ductal carcinoma and lobular carcinoma. Now a day's inborn cases of breast cancer are linked with two genes breast cancer gene one (BRCA1) and breast cancer gene two (BRCA2). The roles of these genes are very important as they maintain the normal growth of breast cells and to stop the growth of cancerous cells. Any kind of abnormalities or mutations in these genes causes the breast cancer. Mutant BRCA1 and BRCA2 genes represent $10 \%$ of all the breast cancers. The most active gene that cause cancer in woman's is BRCA1 that may be a part of genome surveillance complex termed as BASC, a combination of proteins, which play a role in DNA repair like RAD50. The RAD50 complex is composed of protein, i.e. MSH6 and MLH1 heterodimers

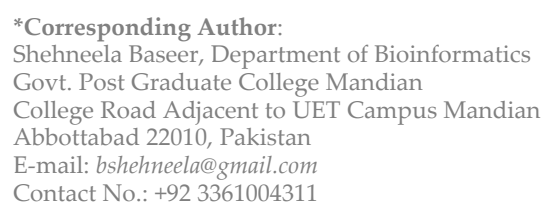

(Jiaxue et al., 2011)

BRCA1 make partnership with RNA polymerase II, a cell-cycle-checkpoint kinase ATR, a chromatinredesigning complex, the Fanconi's weakness protein as FANCD2, SWI and many other vital proteins (Deng and Brodie, 2000; Kerr and Ashworth, 2001). BRCA2 mutations are the sources of expanded lifetime danger of creating ovarian carcinoma. Both BRCA1 and BRCA2 are included in support of genome solidness, particularly the DNA strand repair. BRCA2 gene proteins contain a few duplicates of 70aa motif known as BRC motif, and these motifs interact with RAD51 recombinase, which helps in DNA repair. Tumor silencer quality is present in BRCA2 (Given by RefSeq, Dec 2008). The BRCA1 gene encodes 1863 amino acids residue protein and the gene is located on chromosome 17 at the locus 17q21. Locus compasses $>100 \mathrm{~kb}$ containing 24 exons (Miki et al., 1994).

Human BRCA2 protein is made up of 3418 amino acid residues ( $384 \mathrm{kDa}$ ) and is located at chromosome 13 at locus 13q13.1. The BRCA2 quality is made up of 27 exons and compasses pretty nearly $84.2 \mathrm{~kb}$ of genomic DNA. The N-terminal portion of the BRCA2 protein contains a transcriptional activation space (aa18-105) BRCA2 exon 11 encodes eight rationed motifs termed as $B R C$ repeats. Each of these repeats is made up of around 30 residues. BRCA1 germline transformations account for $50 \%$ of familial ovarian cancers and basically all families with 17q21-linked inborn weakness to ovarian and breast cancer (Hall et al., 1990; Szabo et al., 1995; Easton et al., 1995; Narod et al., 1995).

Changes in both genes (BRCA1 and BRCA2) are not just connected with expanded breast cancer danger but change bearers are additionally defenseless to cancers of the prostate, ovary, male breast and pancreas. Different affiliations can be uncovered when more epidemiological data gets to be accessible (Rahman and Stratton, 1998). Inheritance of the damaged BRCA1 or BRCA2 allele suffices to present tumor inclination. Breast and ovarian 
tumors from inclined people constantly display failure of heterozygosity, while holding the transformed allele showing that the protein results of the qualities may carry on in a few regards as tumor silencers (Schutte et al., 1995). It is confusing, hence, that physical transformation in BRCA2 or BRCA1 don't often occur at random (nonfamilial) in breast cancers (Rahman and Stratton, 1998).

The main objective of the study was to prepare novel synthetic compound to focus on destinations for receptor proteins, located on cells surface, which control the development or stop the multiplication of cancer cells. An effort was done to develop a computer aided drug to control the mutated BRCA1 and BRCA2 genes and to control the expansion of breast cancer in humans.

\section{METHODOLOGY}

\section{Protein structure retrieval and ligand designing}

Many genomic and proteomic online tools were used to evaluate the BRCA1 and crystal structure of a PALB2/BRCA2 complex. The BRCA1/2 protein structures were retrieved by RCSB by applying specification like Xray resolution less than $1.5 \mathrm{~A}^{\circ}$ with organism specification as human. These two protein structures were obtained and were prepared for docking by applying different actions in different tools like discovery studio, chimera and PMV. The ligand modeling steps included drawing of compound through ChemSketch and Chemdraw. The oral toxicity and its dosage were checked by using ProTox. Docking was done by using Hex server and the results of docking were verified by using the Dog site server.

\section{RESULTS}

\section{Proteomics}

The X-ray crystallographic structure of aromatase was retrieved from Protein Data Bank (Berman et al., 2000a; Berman et al., 2000b). Protein structures of BRCA1 and BRCA2 were retrieved from RCSB having PDB id 3K05 and 3EU7. The structures of both proteins were viewed in Discovery Studio. Their water molecules and pervious Dock ligand were removed and were restored in PDB format. The protein structures of BRCA1 and BRCA2 are shown in figure $1 \mathrm{a}$ and $1 \mathrm{~b}$.

\section{Designing of the Compound}

The cumin chemical structure was examined and cumin aldehyde was selected. The toxicity class was not according to our requirement; therefore some structural changes were made in the previous structure of cuminaldehyde. The $\mathrm{CH}_{3}$ group was removed and the functional group was added. The overall structure of the molecule is shown in figure $1 \mathrm{c}$ and its properties are shown in table 1.

\section{Docking}

The molecule binded to a receptor inhibits its function and thus acts as a drug (Marchetti et al., 2011). The 4(1,2,4-triazol-1-ylmethyl)cyclohexane-1-carbaldehyde was docked with the BRCA1 and BRCA2 proteins. The BRCA1 protein amino acids that interact with the ligand are GLN2008, ARG1907, ARG1904， ARG1957， PRO2062, PRO2043, GLY2006, VAL2007, CYS2042 and ALA1903. Of these legends, the two most important are GLN2008 and ARG1907. The structures of BRACA1 proteins are shown in figure $2 a$ and their $2 \mathrm{D}$ structures are shown in figure $2 b$.

The BRCA2 protein interacting amino acids were TYR1108, TYR1064, LEU1142, LEU1143, LEU1092 and PHE1071. The most important among them was the PHE1071. The interactions of amino acids with protein are
Table 1: Showing the lipinsik rule of five and toxicity of the inhibitor.

\begin{aligned} & \hline Particulars Values \\ & \hline Molecular weight 187.0 \\ & Number of hydrogen bond acceptors 3 \\ & Number of hydrogen bond donors 0 \\ & Number of atoms 14 \\ & Number of bonds 15 \\ & Number of rings 2 \\ & Number of rotable bonds 3 \\ & Total charge 0 \\ & Molecular Polar Surface Area 47.78 \\ & Toxicity class, average 6 \\ & \hline\end{aligned}

Table 2: Binding pockets for BRCA1 in the above pockets the cumintrazole analog will show the binding to BRCA1.

\begin{tabular}{|c|c|c|c|c|c|}
\hline Name & $\begin{array}{l}\text { Volume } \\
{\left[\AA^{3}\right]}\end{array}$ & $\begin{array}{c}\text { Surface } \\
{\left[\AA^{2}\right]}\end{array}$ & $\begin{array}{c}\text { Lipo surface } \\
{\left[\AA^{2}\right]}\end{array}$ & $\begin{array}{c}\text { Depth } \\
\text { [Å] }\end{array}$ & $\begin{array}{c}\text { Simple } \\
\text { Score }\end{array}$ \\
\hline P0 & 1703.74 & 2122.68 & 1284.33 & 29.08 & 0.68 \\
\hline P1 & 282.82 & 578.20 & 477.28 & 14.06 & 0.23 \\
\hline P2 & 245.44 & 543.10 & 330.81 & 10.08 & 0.08 \\
\hline P3 & 221.76 & 507.93 & 308.11 & 11.24 & 0.05 \\
\hline P4 & 196.99 & 396.28 & 242.14 & 12.17 & 0.01 \\
\hline P5 & 156.74 & 318.83 & 220.19 & 6.56 & 0.00 \\
\hline P6 & 152.19 & 321.88 & 233.58 & 12.55 & 0.02 \\
\hline P7 & 142.40 & 272.10 & 147.08 & 8.88 & 0.00 \\
\hline P8 & 137.54 & 303.46 & 191.71 & 13.18 & 0.00 \\
\hline P9 & 131.52 & 301.13 & 229.01 & 8.48 & 0.00 \\
\hline P10 & 114.18 & 162.35 & 56.28 & 7.22 & 0.00 \\
\hline
\end{tabular}

Table 3: Binding pockets for BRCA2 in the above pockets the cumintrazole analog will show the binding to BRCA2.

\begin{tabular}{cccccc}
\hline Name & $\begin{array}{c}\text { Volume } \\
{\left[\AA^{3} \text { ] }\right.}\end{array}$ & $\begin{array}{c}\text { Surface } \\
{\left[\AA^{2} \text { ] }\right.}\end{array}$ & $\begin{array}{c}\text { Lipo surface } \\
{\left[\AA^{2} \text { ] }\right.}\end{array}$ & $\begin{array}{c}\text { Depth } \\
{[\mathbf{A}]}\end{array}$ & $\begin{array}{c}\text { Simple } \\
\text { Score }\end{array}$ \\
\hline P0 & 540.35 & 551.08 & 359.88 & 15.07 & 0.35 \\
P1 & 458.75 & 639.57 & 355.05 & 20.06 & 0.26 \\
P2 & 412.22 & 619.48 & 353.29 & 12.22 & 0.28 \\
P3 & 262.53 & 337.64 & 243.51 & 11.83 & 0.12 \\
P4 & 221.95 & 347.74 & 277.28 & 10.95 & 0.20 \\
P5 & 165.50 & 282.01 & 143.12 & 11.84 & 0.00 \\
P6 & 146.82 & 240.15 & 120.39 & 9.94 & 0.00 \\
P7 & 131.97 & 199.13 & 145.78 & 8.56 & 0.00 \\
P8 & 121.79 & 139.17 & 61.71 & 12.59 & 0.00 \\
P9 & 118.53 & 177.14 & 119.90 & 12.30 & 0.00 \\
P10 & 118.21 & 280.90 & 172.90 & 8.37 & 0.00 \\
P11 & 107.90 & 223.00 & 129.83 & 7.27 & 0.00 \\
\hline
\end{tabular}

a)

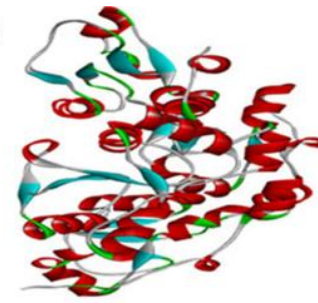

b)
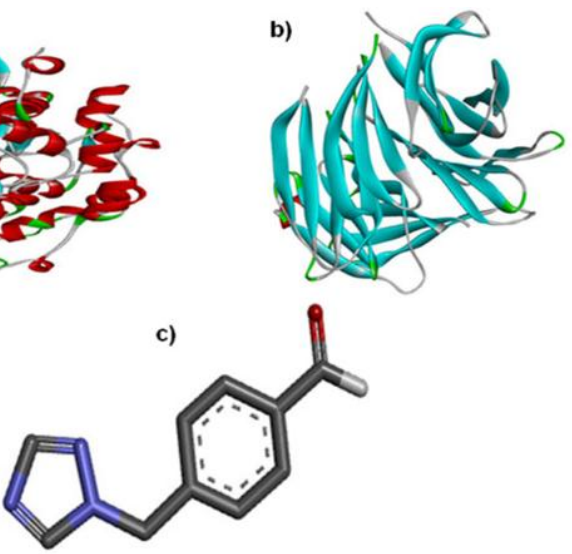

Figure 1: Molecular structure of a) BRCA1 Protein b) BRCA2 Protein c) Cumintrazole analog for BRCA1 and BRCA2 proteins. 


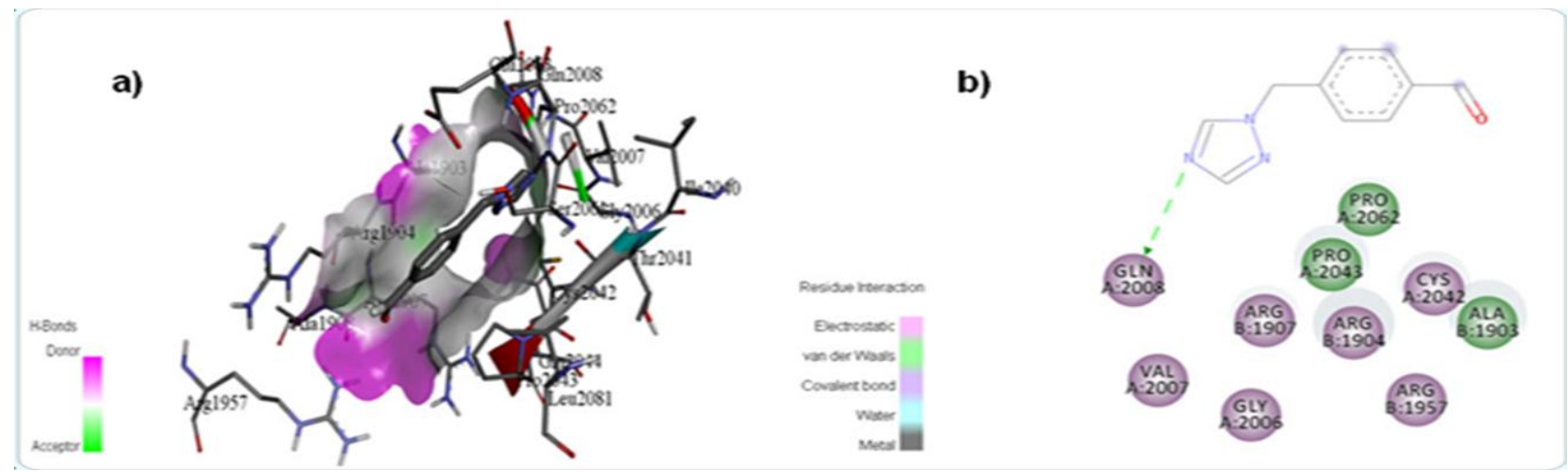

Figure 2: a) Amino acids showing interaction with cumintrazole analog for BRCA1. b) Ligand and interacting residues BRCA1, Ligand docked complex.

a)

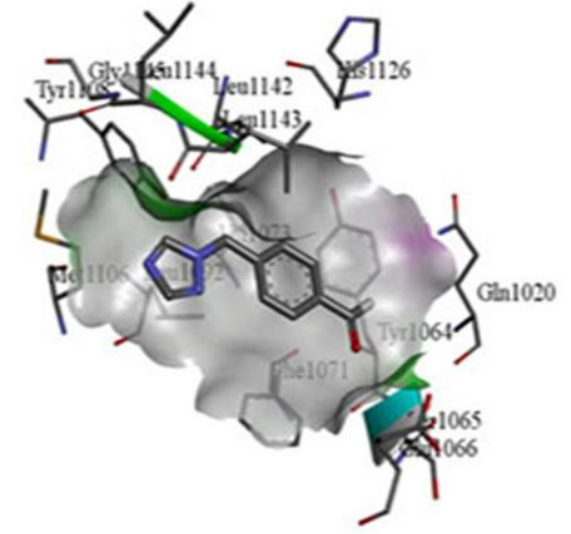

b)

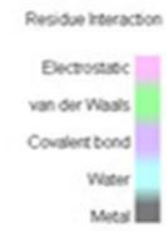

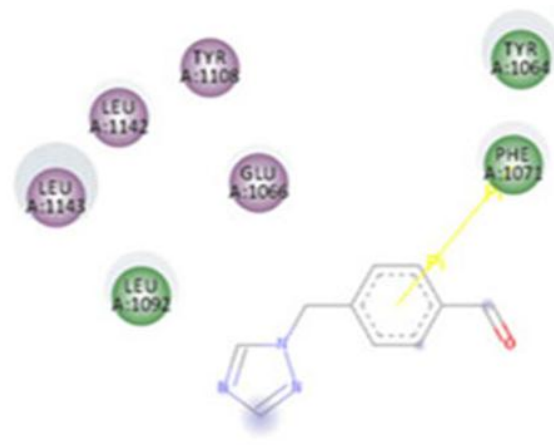

Figure 3: a) Amino acids showing interaction with Ligand in BRCA2. b) Ligand and interacting residues BRCA2, Ligand docked complex.

shown in figure $3 a$ and their $2 \mathrm{D}$ structural diagram is shown in figure $3 b$.

\section{Docking result verification}

The pockets / active sites in BRCA1 were P0, P1, P2, P3, P4, P5, P6, P7, P8, P9 and P10. Our ligand binds to the active site P0. The values of volume, surface, lipo surface depth and simple score are shown in table 2 and these pockets are shown in figure 4a shown by different colors. Figure $4 \mathrm{~b}$ shows the pocket where our analog binds with BRCA1 gene.

The pockets / active sites in BRCA2 are 12, which were named as P0, P1, P2, P3, P4, P5, P6, P7, P8, P9, P10 and P11. Our ligand binds to the active site P1. The values of volume, surface, lipo surface depth and simple score are shown in table 3. These pockets are shown in figure $4 \mathrm{c}$ shown by different colors. Figure $4 \mathrm{~d}$ shows the pocket where our ligand binds with BRCA2.

\section{DISCUSSION}

The 3-dimensional structure expectations of most qualities/proteins prescribe that they can be used further to appreciate the potential segment of breast tumor improvement and some portion of these proteins in raising abnormalities. Also it opens the new entryway of solution getting ready for the better recognizing verification of potential pharmaceutical inhibitors (Zahra et al., 2013). One of the drugs arranging schedules fuse building of ligand and large evaded as receptor-based medication outline. The key purpose of such method is the development of novel structures, not contained in any database (Taha, 2012). We have utilized such approach and attempted to create in-silico novel medication compound for our chosen proteins. Compound was ethyl 3-2\{(diethoxyphosphoryl) methoxy) ethyl\}-4-(4hydroxyphenyl)-6-methyl-2-oxo-1,2,3,4-

tetrahydropyrimidine-5-carboxylate for the synthesis (6i). The $6 \mathrm{i}$ interface with the polar deposit Arg115 by method for hydrogen bonding, while the hydrophobic ring moieties were arranged toward the hydrophobic buildups like Ile133, Phe134, Trp224, Ala306, and Val370 (Yellapu et al., 2013).

Proteins identified with breast cancer and leukemia was focused as macromolecules promyleocytic leukemia, estrogen related and BRCA2. The docking results are positioned by tying energies utilizing LAQ824 as a ligand and BRCA2 as a cancer medication target compound. Additionally communication between BRCA2 (macromolecule) and LAQ824 (ligand) demonstrated LAQ824 associated with SER439, GLU432, ARG435, ASP410, LYS412, ALA413 and LYS414 of BRCA2 protein (Khamkar et al., 2013). It has been observed that Hsp90 was over communicated in numerous breast cancer cells. Hsp90 was docked with co-chaperones, anticancer medications and Hsp90 C-terminal space was docked with its inhibitors analogs of novobiocin. The outcomes demonstrated 
a)
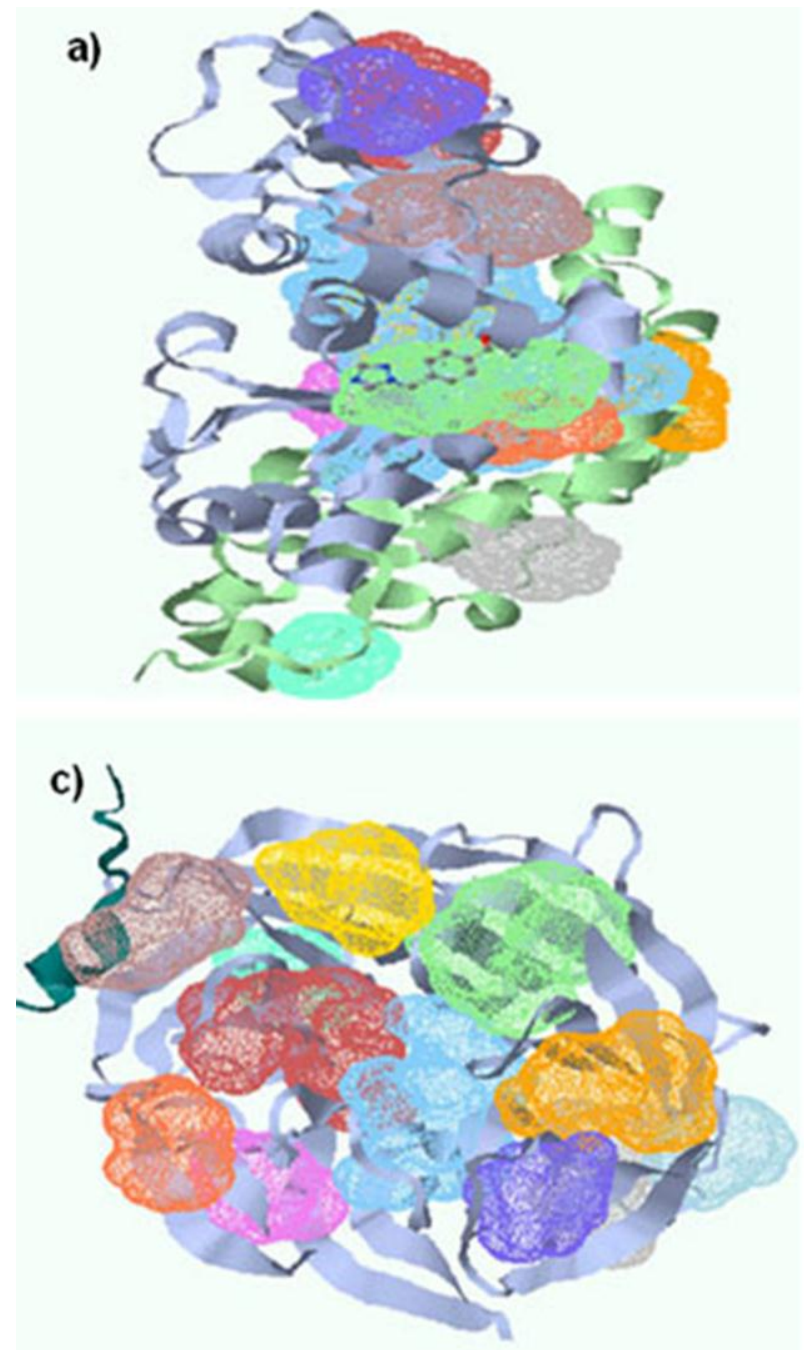

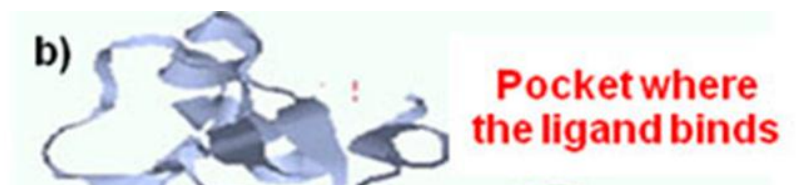

Pocket where
the ligand binds

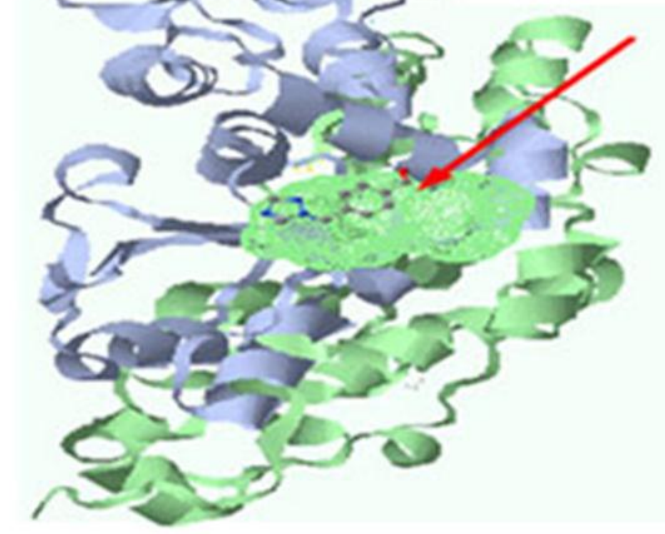

d)

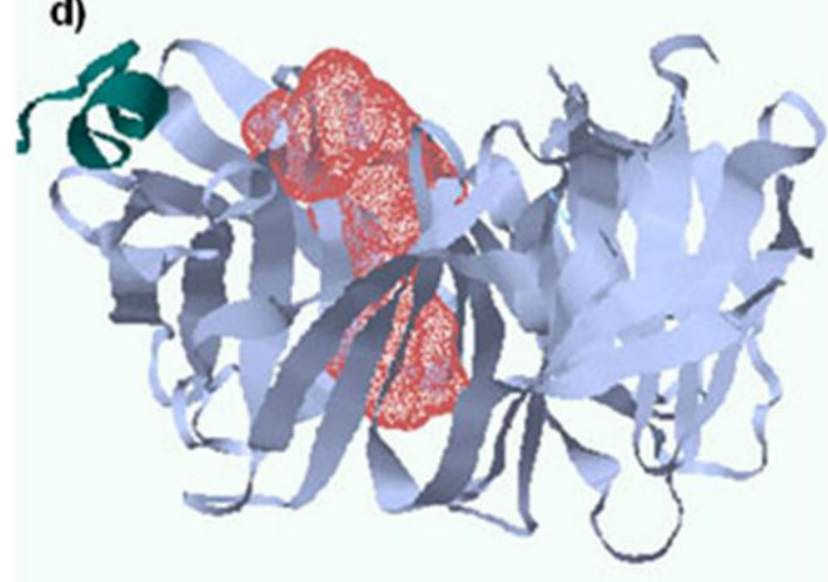

Figure 4: a) All the binding Pockets on BRCA1. b) The Pocket where our analog binds to BRCA 1. c) All the binding Pockets on BRCA2. d) The Pocket where our analog binds to BRCA2.

that Hsp90 had high fondness to tie with Trap1 (Zhu et al., 2012a). These cell lines are broadly acknowledged as models for surveying intense against proliferative action (Zhu et al., 2012). Our proposed drug will show preferred results over these medicines and will help in better survival of patients. Our composed medication simple targets breast cancer's particular qualities, proteins, or the tissue environment that guides in survival of cancer. The medication compound simple confirms relationship with BRCA1 and BRCA2 proteins and impedes their irregular exercises.

\section{CONCLUSION}

In present work, we have taken BRCA1 and BRCA2 proteins, designed the inhibitor molecule [4-(1,2,4-triazol1-ylmethyl) cyclohexane-1-carbaldehyde] for them and docked with these two selected proteins. We investigated that 4-(1,2,4-triazol-1-ylmethyl) cyclohexane-1carbaldehyde compound best fits in the pockets of proteins, which demonstrates its soundness and affirms its drug likeness properties. The amino acid residues PHE and LEU were common among all proteins interacting pockets. The larger part of the financially open pharmaceuticals may misuse couple of the properties of Lipinski guideline of five. However our medication is totally fulfilling the Lipinski standards of five with qualities having Log value of P0.89, dissolvability -1.87 , drug similarity -3.47 , over drug score of $0.3, \mathrm{H}$ bond acceptors 3.1 and donor 0 individually. We checked the danger levels, and wellbeing impacts of medications; that are utilized to cure breast cancer. We presume that our medication is better than business drugs accessible in business sector. As it is non-lethal in nature and has no side reactions. In future, this work can be further used as a piece of clinical trials to test its sufficiency and social focal point.

\section{ACKNOWLEDGEMENT}

We are thankful to Ms. Dilshad Akhtar for her suggestions and naming of the compound as Cumintrazole analog. We are grateful to Miss Shumila Azam for her valueable suggestions and technical support during this work. We are also grateful to Mr. Azhar Mehmood, Chairman, Department of Bioinformatics and Prof. Dr. 
Shakeel Mufti, Principal, GPGC Mandian Abbottabad for their support during the research work.

\section{AUTHOR'S CONTRIBUTION}

The experiment was designed and performed by Shehneela Baseer, who performed all exercises till paper write up. Research work and paper write up was done under the supervision of Sajid Khan. Dr. Faisal Nouroz supervised the whole research work and helped in the preparation of final manuscript.

\section{REFERENCES}

Berman, H.M., Bhat, T.N., Bourne, P.E., Feng, Z.K., Gilliland, G., Weissig, H. et al. (2000a) The Protein Data Bank and the challenge of structural genomics. Natural Structural Biology, Volume 7, Pages 957-959. [DOI]

Berman, H.M., Westbrook, J., Feng, Z., Gilliland, G., Bhat, T.N., Weissig, H. et al. (2000b) The Protein Data Bank. Nucleic Acids Research, Volume 28, Issue 1, Pages 235-242. [DOI]

Cornelis, R.S., Neuhausen, S.L., Johansson, O., Arason, A., Kelsell, D. Ponder, B.A., Tonin, P., Hamann, U., Lindblom, A., Lalle, P. et al. (1995) High allele loss rates at 17q12-q21 in breast and ovarian tumors from BRCAl-linked families. The Breast Cancer Linkage Consortium. Genes Chromosomes Cancer. Volume 13, Issue 3, Pages 203-210. [DOI]

Deng, C.X. and Brodie, S.G. (2000) Roles of BRCA1 and its interacting proteins. Bioessays Volume 22, Pages 728-737. [DOI]

Easton, D.F., Ford, D. and Bishop D.T. (1995) Breast and Ovarian Cancer Incidence in BRCA I-Mutation Carriers. Breast Cancer linkage Consortium. American Journal of Human Genetics, Volume 56, Issue 1, Pages 265-271. PMid:7825587

Easton, D.F. (1999). How many more breast cancer predisposition genes are there? Breast Cancer Research, Volume 1, Pages 14-17. [DOI]

Hall, J.M., Lee, M.K., Newman, B., Morrow, J.E., Anderson, L.A., Huey, B. and King, M.C. (1990) Linkage of early-onset familial breast cancer to chromosome 17q21. Science, Volume 250, Pages 1684-1689. [DOI]

Kerr, P. and Ashworth, A. (2001) New complexities for BRCA1 and BRCA2. Currents in Biology, Volume 11, Pages 668-676. [DOI]
Khamkar T, Abhyankar, M., Tendulkar, G, Khanna, V.G and Kannabiran, K. (2013) In Silico Molecular Docking of Marine Drugs Against Cancer Proteins. Advances in Chemical Science, Volume 2, Pages 24-29. [Link]

Miki, Y., Swensen, J., Shattuck-Eidens, D., Futreal, P.A., Harshman, K., Tavtigian, S., Liu, Q., Cochran, C., Bennett, L.M. and Ding, W. et al. (1994) A strong candidate for the breast and ovarian cancer susceptibility gene BRCA1. Science. Volume 7, Issue 266, Pages 66-71. [DOI]

Narod, S.A., Ford, D., Devilee, P., Barkardottir, R.B., Lynch, H.T., Smith, S.A., Ponder, B.A., Weber, B.L., Garber, J.E. and Birch, J.M. et al. (1995) An evaluation of genetic heterogeneity in 145 breast-ovarian cancer families. Breast Cancer Linkage Consortium. American Journal Human Genetics, Volume 56, Issue 1, Pages 254-264. PMid:7825586

Nathanson, K.N., Wooster, R. and Weber, B.L. (2001) Breast cancer genetics: what we know and what we need. Nature Medicine, Volume 7, Pages 552-556. [DOI]

Rahman, N. and Stratton, M.R. (1998) The genetics of breast cancer susceptibility. Annual Review Genetics, Volume 32, Pages 95-121. [DOI]

Schutte, M., da Costa, L.T., Hahn, S.A., Moskaluk, C., Hoque, A.T., Rozenblum, E., Weinstein, C.L., Bittner, M., Meltzer, P.S. and Trent, J.M. (1995) Identification by representational difference analysis of a homozygous deletion in pancreatic carcinoma that lies within the BRCA2 region Proceedings of Natural Academy of Sciences of USA, Volume 92, Issue 13, Pages 5950-5954. [DOI]

Szabo, C.I. and King, M.C. (1995) Inherited breast and ovarian cancer. Human Molecular Genetics, Volume 4, Pages 1811-1817. PMid:8541881

Taha, M.O. (2012) Virtual screening. Croatia: Intech. Pages 01-108. [DOI]

$\mathrm{Wu}$, J., Lu, L-Y. and Yu, X. (2011) The role of BRCA1 in DNA damage response. Protein Cell, Volume 1, Issue 2, Pages 117-123. [DOI]

Yellapu, N.K., Atluri. N., Kandlapalli, K., Kilaru, R.B., Vangavaragu, R.J., Osuru, H., Chamarthi, N., Sarma P.V.G.K. and Matcha, R. (2014) Design, synthesis, in silico, and in vitro evaluation of novel pyrimidine phosphonates with cytotoxicity against breast cancer cells, Medicinal Chemistry Research, Volume 23, Pages 317-328. [DOI]

Zhu, W., Liu, Y., Zhao, Y., Wang, H., Tan, Li., Fan, W. and Gong, P. (2012) Bismorpholino pyrimidine and 1,3,5-triazine derivatives as potential antitumor agents. Archiv der Pharmazie, Volume 345, Issue 10, Pages 812-821. [DOI] 